\title{
The Influence of Sports Activities on College Students' Social Adaptability
}

\author{
https://doi.org/10.3991/ijim.v15i14.24801 \\ Lei $\left.\mathrm{Hu}^{(}\right)$, Manoch Prompanyo \\ Shinawatra University, Bangkok, Thailand \\ Leihu1979@163.com
}

\begin{abstract}
The cultivation of talents has always been the basis of the development of economy, science and technology and the overall strength of all countries. With the further deepening of China's reform and opening up, the rapid development of the market economy and the gradual improvement of the level of information technology, the education sector is paying more attention to the cultivation of talents in all walks of life in China. As for college students is about to walk into society, how to learned during college all kinds of professional knowledge and skills in the future life and work, how reasonable in the future workplace, properly handle interpersonal relationships, how to better integrate into social life, reflect their own value, and to raise their competitive strength, and observe the rules and regulations, laws and regulations, Have a good moral integrity, set up the correct world outlook, outlook on life, values. All these are closely related to the social adaptability of college students. Physical education is an important way to implement quality-oriented education and cultivate talents with all-round development, which was clearly pointed out in the Guidelines for Physical Education Course Teaching in National Colleges and Universities issued in 2002.In the given physical education teaching objectives also explains that the students are required to show good sports ethics and cooperative spirit as well as correctly deal with the relationship between competition and cooperation.
\end{abstract}

Keywords-Physical Activities, College Students, Social Adaptability

\section{Introduction}

The Olympic spirit contains the content of developing good social adaptability. Sports advocate the Olympic spirit. The Olympic spirit is mutual understanding, friendship, unity and the fair competition spirit, of all kinds of sports activities of colleges and universities also follow the Olympic spirit, through the teachers guide students to complete on sports skill learning, of good health and to form a good habit of sports at the same time also can cultivate students' human's pursuit of good qualities such as fairness and justice. Good social adaptability is an indispensable personal quality in China's economy and society [1-6]. Since China joined the World Trade Organization (WTO) in 2001, China's economy has developed rapidly and the overall 
quality of its people has also been increasing. But at the same time, under the impact of foreign politics, economy and culture, China's politics, economy, education, society, culture and so on have become more complex and changeable. In today's society, the society needs talents to play an active role in the development of the social economy, and the ability to adapt to the society should be excellent, their body should be healthy [7-13].

It can be seen that the ability of social adaptation is one of the important abilities for college students to participate in social work and life and maintain physical and mental health for life, which is to adapt to the requirements of China's economic construction on students. As one of the important ways to cultivate college students, colleges and universities participate in sports activities is an important part of college life, but also to a certain extent, undertake the obligation and responsibility of cultivating the social adaptability of college students [14-19].

This study is based on the research of ordinary colleges and universities and the absorption of the existing research results on the basis of the current situation, the adaptability of the social ability of college students and suggestions, to provide a reference for college educators to guide college students to better adapt to the future society. It is mainly reflected in the following aspects:

1. Student development: To grasp the status quo of social adaptability of college students, analyze the existing problems and their influencing factors, and put forward targeted suggestions to solve the problems of social adaptability of college students, which is conducive to improving the social adaptability of college students and promoting their comprehensive and healthy development.

2. School Management: Through school research, we can fully understand the characteristics of college students. The obtained data, original data and research conclusions can provide reference for the work of social adaptability of college students in Chongqing and the improvement of the education and management efficiency of social adaptability of college students.

3. Theoretical basis: to put forward a report for reference on the construction and development of the present stage of college physical education teaching, and to provide a theoretical basis for the subsequent preparation of college physical education courses and the organization of sports activities.

4. Mental health guidance: The survey data and conclusions of this study can provide reference for psychological guidance and psychological intervention on social adaptability of college students.

\section{$2 \quad$ Literature Review}

\subsection{Domestic Research Status}

In recent years, in order to improve the social adaptability of college students, more and more scholars have studied it. Through the knowledge network in China refer to, in order to "university (or college) sports" "the social adaptation ability" as the keyword search, found according to the total of 664 article, through the filter, after 
the part of the literature research findings: first, China's college students there are some problems in social adaptation ability aspect, there are quite a number of university students have psychological problems in different degree. For example, Ma Jianhua found that $15 \%$ of the 5022 college students had different degrees of psychological problems when he conducted a survey on their mental health in the article "Investigation and Reflection on the Mental Health of College Students". It can be seen that the social adaptability of college students is not optimistic. However, in the research of Lv Heli, Jin Huijuan and Chen Zhiqiang, it is found that college physical education has an obvious effect on promoting the mental health of college students. Yan Ke difficult and Yan Lijie in sports activities for the cultivation of the ability of social communication, the article also demonstrates the sports activities in the human society to cultivate the students' comprehensive ability of irreplaceable advantages with other disciplines, growth and development of sports in people play a very important role in the process, physical activity can cultivate their interpersonal ability, competition and cooperation ability, social emotions and down resistance force [20].

The research also found that college students' personal values and life goals affect their ability to adapt to college life. If their life goals and personal values are in line with the development of society, college students can adapt to the environment well; otherwise, it is difficult for them to adapt. Many domestic studies have found that the social adaptability of college students is closely related to their mental health. Students with high psychological adaptability can adapt well to the society and university, so their mental health and self-development will be better [21]. To facilitate the uniform standard, to adapt to the domestic research on college students to adapt to the education, the Ministry of Education of the college students' mental health assessment system developed for college students in China college student adjustment scale (CCSAS) of the People's Republic of China, and actual survey in domestic colleges and universities, establish the norm of the college students' adaptability to investigate, its high reliability and practical value.

\subsection{Foreign Research Status}

Foreign scholars studied the social adaptive education of college students earlier, developed a relatively complete and highly reliable survey scale, and the intervention methods adopted have achieved remarkable results. Psychologist Nit believes that every stage of life is a process of adaptation. From high school to university transition, college students face a new environment, with the change of life, learning and interpersonal environment, easy to produce psychological discomfort, and even adaptive barriers, this is college students to adapt [22]. In 1971, the United States created a new teaching concept and curriculum model: Project Adventure, which is one of the middle school courses in the United States. Its emphasis on the cultivation of students' psychological adaptability includes the adaptation to the natural environment, psychological environment and life environment after change. British scholars Dyson, Rachael et al. found through investigation that college students have difficulties in adapting to college life. College life is full of novelty and challenges for college students, and they often have psychological adjustment barriers. Moreover, there are 
gender differences, and male and female students have different emphasis on difficulties in adapting to college life. German scholars Sasaki and Megumi et al. studied the influence of emotion, cognition, social support and other factors on the adaptability of college students and the relationship between them. They pointed out that it is necessary to help freshmen adapt by changing their cognition and training their problemsolving ability. South Korea Seoul area has the scholar to carry on the investigation, the discovery because other class hour increases, the physical education class hour relative reduction caused about $20 \%$ student appeared to be unable to reach the normal physical strength, the study result drops, the interpersonal communication frequency decreases. And the school in the increase of physical education class, and encourage students to carry out all kinds of sports activities, actively participate in sports associations, students' physical strength, performance and interpersonal communication frequency have different degrees of improvement [23].

Through the above research status and research background, it is not difficult to see that first, social adaptation ability has a significant impact on college students after they enter the society. Secondly, Chinese college students and their graduates are still weak in social adaptability. Third, whether at home or abroad, the ability to adapt to society has attracted wide attention from all walks of life. Fourthly, the spiritual quality cultivated by physical education can play a positive role in the overall and healthy development of individuals. These are also related to the development of national science, technology, and economy to a certain extent.

\section{$3 \quad$ Research Methods}

\subsection{Research Hypothesis and Research Ideas}

This study attempts to investigate the number, time, items and intensity of sports activities that college students participate in during their college years. This paper analyzes and sums up the influence of college sports activities on the social adaptability of college students, and proves that college sports activities have a positive influence on the various components of college students' social adaptability, thus contributing to the cultivation, development and adjustment of college students' social adaptability as a whole.

H1: There is a significant correlation between the statistical variables of college students' physical activity and their social adaptability (learning, life and interpersonal relationship).

H2: There is a significant correlation between social support and college students' social adaptability (study, life and interpersonal relationship).

\subsection{Research Methods}

This study takes the influence of sports activities on the social adaptability of college students as the research object, through the investigation and analysis of 450 
college students in Chongqing University to participate in sports activities, to study the influence of sports activities on the social adaptability of college students.

Questionnaire survey. This study investigates the current situation of the adaptability of ordinary undergraduates in colleges and universities in Chongqing. The stratified random sampling method was used to investigate 14 departments of four universities in Chongqing (Chongqing Technology and Business University, Chongqing Second Normal University, Chongqing Jiaotong University, Chongqing University of Posts and Telecommunications). This questionnaire survey will be distributed in the middle of June 2020 and collected at the end of June. A total of 450 questionnaires were sent out and 421 were received with a recovery rate of $93.56 \%$. Among them, 408 were effective and the effective rate was $90.67 \%$.

Data statistics. In this study, SPSS20.0 data statistical software was used to conduct statistical analysis of the valid questionnaires after the questionnaires were collected. The main applications are as follows: 1) The reliability and validity of the questionnaire were tested according to Kaiser-Meyer-Olkin value and Cronbach's Alpha value. 2) Through frequency and percentage statistics, the basic situation of the sample is described. 3) Independent-sample Test and single-factor Analysis of Variance are used to Test the differences in demographic variables of college students' social adaptability. 4) Through correlation test, analyze the correlation between college students' social support (school support, peer group support, family support) and college students' social adaptability.

Logical analysis. Logical analysis Through logical analysis methods such as induction, comparison, analysis and synthesis, I studied the relevant content of this topic on the basis of previous scholars' research data and my own teaching observation and analysis.

Research and interview method. According to the requirements of the thesis, the author with the issues related to this study successively visited and asked about 23 experts, professors, and with several universities of relevant experts surveyed, leadership, and its communication and communication, and seek advice and Suggestions on this topic, in order to improve sports activities of college students' social adaptation ability questionnaire work etc. Further interviews with students, counselors and case studies made this study more detailed and comprehensive.

\section{$4 \quad$ Results and Analysis}

\subsection{Research Results}

The general situation of college students' social adaptability. Through the analysis of the obtained data, the results are shown in Table 1.

According to Table 1, according to the diagnostic scale of social adaptability, the average score of social adaptability of college students is 23.5 , which is at the average level of social adaptability. The average difference between men and women was not significant, but boys scored slightly higher than girls. 
Paper-The Influence of Sports Activities on College Students' Social Adaptability

Table 1. Overall situation of college students' social adaptability

\begin{tabular}{|l|c|c|c|}
\hline \multicolumn{4}{|c|}{ Social Adaptation } \\
\hline \multicolumn{1}{|c|}{ Gender } & $\boldsymbol{N}$ & Mean & Standard deviation \\
\hline Male & 190 & 23.05 & 8.503 \\
\hline Female & 218 & 23.95 & 9.102 \\
\hline Total & $\mathbf{4 0 8}$ & & \\
\hline
\end{tabular}

\subsection{Analysis of the Effect of Physical Activities on College Students' Social Adaptability}

Newly enrolled students may feel restless because they will not be able to adapt to the new learning mode for some time. At the same time, the knowledge learned in university is more systematic, professional and complex. Some college students will find it difficult to adapt to the new learning environment and new learning methods, and feel pressure for the completion of courses and examinations.

Sports activities will increase people's oxygen intake, make people easier to relax themselves, achieve the role of emotional stability, eliminate the anxiety and pressure caused by various problems and psychological tension of college students, help college students through the adaptation period of college study. At the same time, it can also promote the physiological function of college students and help the enhancement of their learning ability from the most fundamental point of view. Li Ze, a former scholar, found that the students of three classes had improved their learning adaptability to a certain extent after learning the sports dance course for nine weeks. Sports to the cognitive ability of human beings from the social status or the role of cognition. In sports, athletes, referees, coaches and even court staff all play a specific role. In their own positions and roles, they are responsible for different related work, when each role player can effectively and actively complete their own work, to ensure the smooth completion of a sports competition. Each person plays a different role on the same team. Soccer players, for example, are divided into strikers, midfielders, defenders, goalkeepers, and so on. Lu Qiang concluded in his research that calisthenics training has a positive effect on college students' role adaptation ability.

Through the above analysis and research results, college sports activities have a positive impact on the learning adaptability of college students. The physical education teaching mode in universities is more humanized, gradually changing from teaching-centered to student-centered, and the choice of physical education classes is in the hands of students. By setting up different physical education specialized courses, college students can freely choose the sports they are interested in for study and exercise. 


\section{Conclusions and Measures}

\subsection{Corresponding Measures for Students to Improve Their Social Adaptability}

Positioning yourself correctly and striving to improve yourself. For college students, on the one hand, to the school and with the help of the teacher's guidance, education, on the other hand, is more important on the one hand, is the college students to improve and continue to exercise their own ability to adapt, to fully realize that this ability to adapt to the environment of the gain is not only to adapt to the current environment has a direct practical significance, And for the future to adapt to a variety of environmental changes also has a very important significance. Therefore, students should regard the adaptation to the current university environment as a challenge, as well as an important opportunity to improve and develop themselves. Establish a correct world view. Mental health is first reflected in a person's healthy attitude towards life. Setting up a correct outlook on life is the first essential to strengthen frustration tolerance and promote mental health. This requires an open attitude to life and a willingness to learn new experiences; Learn to see things, others and yourself in a positive light.

Set lofty ideals and cultivate optimism. Dare to face up to the reality, dare to face the setbacks, only to their own career of unlimited loyalty and persistent pursuit, it is possible to overcome the interference of various bad emotions, overcome all kinds of difficulties, with setbacks and failures paved the way to success. Practice has also proved that unambitious, short-sighted, narrow-minded, vulgar taste, sentiment is not high, the lack of education of the people, the most easy to produce emotional fluctuations, moodiness and some irrational behavior. This requires us to be open, dialectical, rational attitude towards life, willing to accept new things, accept new experience; Learn to see yourself and others and the world around you in a positive, developmental light; Enhance the spirit of altruism, enhance professional dedication and so on. In a word, only by setting up correct and lofty ideals can we effectively regulate our emotions and be the master of our emotions. Emotion and emotion are people's experience of whether objective things are in line with people's needs.

Establish a correct view of love. The love problem of college students, with the increasingly common love phenomenon, has caused the school, the society, the family's high attention and attention. The attitude of college students to love develops from prohibiting to not advocating, not opposing, and finally to admitting the reality and giving reasonable guidance. Correct love values require the unity of love and career, take love as one of the important driving forces for career success, and when necessary, bravely sacrifice love and obey the cause; Ask for sincere and pure love; Require like-minded and emotional resonance; Requirement of single-minded love and lasting feelings.

Develop interpersonal skills. Whether the interpersonal relationship is good or not has become an important factor affecting college freshmen. Communication activities accompany people's life, is one of the basic needs of people. College relationships are the starting point for adult relationships throughout life. Good atmosphere 
can promote the development of college students; And bad atmosphere is easy to occur bad mood, strengthen or occur bad personality and personality quality, and then some behavioral problems. A philosopher said, "A man without communicative skills is like a ship on land, never reaching the great sea of life." College students learn knowledge, understand themselves, get new life and love, all happen in interpersonal communication, people are social people, without interpersonal communication, can not survive.

\subsection{Improvement Measures That Schools and Teachers Should Take to Improve the Social Adaptability of College Students}

Change the concept of mental health education. The education of college students' psychological adaptation is the foundation and important link of college students' health education. However, at present, there is still a lack of understanding and theoretical research on the special psychological adaptation education for college students, which cannot meet the needs of students, and its importance and urgency have not been fully recognized. Set up the mental health education concept of "psychological education, focusing on the foundation", the students' mental health education runs through and implements to the whole stage of student education, and changes the students' mental health education only to a few or even individual students' psychological problems for counseling, consultation and treatment.

Carry out targeted social adaptation education for college students. The process of college students' social adaptation is multi-faceted, complex, potential and universal. Therefore, it is undoubtedly an important way to improve the level of students' mental health, optimize their psychological quality and improve their mental health to carry out psychological adaptation education systematically for college students. Should be freshman courses in special psychological health, as a compulsory course, and mental health class teaching must knot and the new practice, enrich the teaching content to be combined with knowledge and interest, improving teaching methods, through case teaching, experience more activity, expert lectures, behavior training, do participatory and operability, so as to improve the effect of education, Make the students understand the mental health knowledge, establish the mental health consciousness, optimize the individual psychological quality, enhance the ability of psychological adjustment, prevent and alleviate the psychological problems, guide them to deal with the new environment to adapt to, the improvement of learning methods, interpersonal communication, making friends and love, personality development, emotional regulation and other aspects of the problem.

Increase investment to improve the scientific degree of social adaptation education. The problem of funds is the bottleneck of mental health education in colleges and universities. The necessary investment is the material premise and guarantee of carrying out mental health education in colleges and universities. Network technology is widely used in school mental health education activities, the students' psychological measurement has been can be done directly on the computer, storage, management and use of various psychological archives is no longer a manual processing, the Internet, new media can give students more information, to increase the psychological 
counseling of universality and adaptability, By establishing an expert system of school psychological counseling and guidance, students can directly seek the assistance and guidance of some experts according to their own situations and needs. In short, convenient, fast and abundant modern technical means will provide technical guarantee for students' mental health education.

Gradually establish and improve the psychological counseling system for college students. Schools should vigorously strengthen the construction of psychological counseling system. At the same time, certain measures can be taken in the student enrollment work. For example, after students enter school, they are surveyed with a mental health questionnaire, which builds a mental health profile for each student. To provide psychological consultation services or necessary psychological treatment to freshmen with serious psychological problems; And the students' mental health is regularly tested; Establishment of psychological counseling clinics or centers; At the same time, a homepage of psychological counseling should be established on the campus website to carry out online psychological counseling or anonymous telephone counseling. Because of the anonymity of the network or telephone, this is not only conducive to keeping the confidentiality of the parties concerned, but also conducive to eliminating the concerns of students and stating their inner perplexities and problems in a real and detailed way. Adhere to the principle that students seek help voluntarily and counselors take the initiative to discover problems and solve problems, carry out regular psychological counseling.

\subsection{Measures for Families to Improve the Social Adaptability of College Students}

As a social person, the new life circle is transferred from the family to the school, and then from the school to the society. The influence of the original family on students' mental health is profound and long-lasting. Just as Marx and Engels said, "the family is the only social relationship at the beginning", although the modern family is no longer the only social relationship, but for individual, he is still the earliest social relationship. Questionnaires, interviews and surveys show that whether the family education is appropriate and whether the family atmosphere is harmonious will affect the mental health of students. Therefore advise parents to strengthen the students' learning related knowledge of education, to explore their children's family education mode, parents keep a good state of mind, to overcome the adverse psychological state such as comparison and burn out, hope to have good mental health status, parents level build harmonious family atmosphere, to student's mental health will play a positive role in promoting.

\subsection{Physical Activities Improve College Students' Social Adaptability}

There is no significant difference between male and female, between grades and between majors in college students participating in sports. The social adaptability index of college students varies with the sports they participate in. Basketball, volleyball and football have the highest social adaptability index, and they are evaluated as 
having strong social adaptability. Tennis, badminton, table tennis students' social adaptability index is good; The social adaptability index of walking, running, Wu Shu and other personal sports was poor. The social ability index of college students participating in sports is positively correlated with the increase of The Times of weekly exercise and the intensity of sports load. College students participating in sports can harmonize interpersonal relationship, improve interpersonal relationship ability and social adaptability.

\section{References}

[1] Kochenderfer, B.J., Ladd, G.W. (1996). Peer victimization: Cause or consequence of school maladjustment? Child development, 67(4), 1305-1317. https://doi.org/10.1111/ j.1467-8624.1996.tb01797.x

[2] Luna, P., Rodríguez-Donaire, A., Rodrigo-Ruiz, D., Cejudo, J. (2020). Subjective wellbeing and psychosocial adjustment: Examining the effects of an intervention based on the sport education model on children. Sustainability, 12(11), 4570. https://doi.org/10.3390/su12114570

[3] Bailey, J.A. (2021). Building learning capacity in an age of uncertainty: Leading an agile and adaptive school. Routledge. https://doi.org/10.4324/9781003144847

[4] Han, M.Q., Zhou, N., Qiao, Z.M. (2020). Analysis of extension strategies for improving adaptive teaching ability of college teachers. International Journal of Emerging Technologies in Learning, 15(15), 147-161. https://doi.org/10.3991/ijet.v15i15.15927

[5] Ren, Y.J., Tang, R., Jiang, X. (2020). Three track teaching mode of sports anatomy based on innovative theory. International Journal of Emerging Technologies in Learning, 15(24), 75-88. https://doi.org/10.3991/ijet.v15i24.18959

[6] Liu, Y., Zhu, T.Q. (2020). Individualized new teaching mode for sports biomechanics based on big data. International Journal of Emerging Technologies in Learning, 15(20), 130-144. https://doi.org/10.3991/ijet.v15i20.17401

[7] Siedentop, D., Van der Mars, H. (2004). Introduction to physical education, fitness, and sport.

[8] Liu, H.Y., Chao, C.Y., Kain, V.J., Sung, S.C. (2019). The relationship of personal competencies, social adaptation, and job adaptation on job satisfaction. Nurse education today, 83, 104199. https://doi.org/10.1016/j.nedt.2019.08.017

[9] Ota, M., Takeda, S., Pu, S., Matsumura, H., Araki, T., Hosoda, N., Yamamoto, Y., Sakakihara, A., Kaneko, K. (2020). The relationship between cognitive distortion, depressive symptoms, and social adaptation: A survey in Japan. Journal of affective disorders, 265, 453-459. https://doi.org/10.1016/j.jad.2020.02.045

[10] Barriga, A.Q., Landau, J.R., Stinson, B.L., Liau, A.K., Gibbs, J.C. (2000). Cognitive distortion and problem behaviors in adolescents. Criminal justice and behavior, 27(1), 36-56. https://doi.org/10.1177/0093854800027001003

[11] Xu, Z.H. (2020). Construction and optimization of talent training quality based on da-ta mining. Ingénierie des Systèmes d'Information, 25(4), 419-425. https://doi.org/ $\underline{10.18280 / \text { isi. } 250403}$

[12] Hu, Y.D., Li, X.Y. (2020). An evaluation model of comprehensive human resources quality of financial enterprises based on deep neural network. Ingénierie des Systèmes d'Information, 25(5), 629-636. https://doi.org/10.18280/isi.250510 
[13] Ding, H., Li, X.N., Dai, J.W., Xue, Y.Q. (2020). Spatial distribution of UNESCO glob-al geoparks in China and its influencing factors. International Journal of Design \& Na-ture and Ecodynamics, 15(1), pp. 47-55. https://doi.org/10.18280/ijdne.150107

[14] Rieu, A.M. (2021). Managing knowledge, governing society: Social theory, research policy and environmental transition. CRC Press.

[15] National Academies of Sciences, Engineering, and Medicine. (2021). Mental health, substance use, and wellbeing in higher education: Supporting the whole student. National Academies Press. https://doi.org/10.17226/26015

[16] Pang, B., Rossi, T. (2021). Diversity, difference and social justice in physical education: Challenges and strategies in a translocated world. CRC Press.

[17] Simon, L., Roland, R. (1995). Test of reaction and adaptation in college (TRAC): A new measure of learning propensity for college students. Journal of Educational Psychology, 87(2), 293-306. https://doi.org/10.1037/0022-0663.87.2.293

[18] Beaumont F., Bogard F., Murer S., Polidori G., Madaci F., Taiar R. (2019). How does aerodynamics influence physiological responses in middle-distance running drafting? Mathematical Modelling of Engineering Problems, 6(1), 129-135. https://doi.org/10. 18280/mmep.060117

[19] Perić, M., Đurkin, J., Vitezić, V. (2018). Active event sport tourism experience: The role of the natural environment, safety and security in event business models. International Journal of Sustainable Development and Planning, 13(5), 758-772. https://doi.org/10.2495/ sdp-v13-n5-758-772

[20] Afshar, P.F., Foroughan, M., Vedadhir, A., Tabatabaie, M.G. (2017). Psychometric properties of the Persian version of Social Adaptation Self-evaluation Scale in communitydwelling older adults. Clinical interventions in aging, 12, 579-584. https://doi.org/10.2147/ cia.s 129407

[21] Paiva, M.L., Lima, E.M., Siqueira, I.B., Rzezak, P., Koike, C., Moschetta, S.P., ... \& Valente, K.D. (2020). Seizure control and anxiety: Which factor plays a major role in social adjustment in patients with Juvenile Myoclonic Epilepsy? Seizure, 80, 234-239. https://doi.org/10.1016/j.seizure.2020.06.033

[22] Ip, H.H., Wong, S.W., Chan, D.F., Byrne, J., Li, C., Yuan, V.S., Lau, K.S.Y., Wong, J.Y. (2018). Enhance emotional and social adaptation skills for children with autism spectrum disorder: A virtual reality enabled approach. Computers \& Education, 117, 1-15. https://doi.org/10.1016/j.compedu.2017.09.010

[23] Anderson, C.M. (1998). Aggressive communication traits and their relationships with the cognitive flexibility scale and the communication flexibility scale. Journal of Social Behavior and Personality, 13(3), 531-540.

\section{$7 \quad$ Authors}

Lei Hu is a student at the School of Management, Shinawatra University in Thailand. He is also a teacher and associate professor of Chongqing Technology and Business University (Leihu1979@163.com), mainly studying physical education, sports management, sports training and so on.

Manoch Prompanyo is a doctoral tutor and full-time teacher at the School of Management, Shinawatra University (manoch.p@siu.ac.th). At Shinawatra University, he mainly teaches research methods, management and other courses.

Article submitted 2021-05-15. Resubmitted 2021-06-21 Final acceptance 2021-06-21. Final version published as submitted by the authors. 